\title{
The Use of Le Bail Method to Analyze the Semicrystalline Pattern of a Nanocomposite Based on Polyaniline Emeraldine-Salt Form and $\alpha-\mathrm{Al}_{2} \mathrm{O}_{3}$
}

\author{
Edgar A. Sanches, ${ }^{1}$ Adriano de S. Carolino, ${ }^{2}$ Amanda L. dos Santos, ${ }^{3}$ \\ Edson G. R. Fernandes, ${ }^{4}$ Daniela M. Trichês, ${ }^{1}$ and Yvonne P. Mascarenhas ${ }^{4}$ \\ ${ }^{1}$ Programa de Pós-Graduação em Ciência e Engenharia de Materiais (PPGCEM), Programa de Pós-Graduação em Física (PPGFIS), \\ Universidade Federal do Amazonas (UFAM), 69077-000 Manaus, AM, Brazil \\ ${ }^{2}$ Departamento de Física (DF), Universidade Federal do Amazonas (UFAM), 69077-000 Manaus, AM, Brazil \\ ${ }^{3}$ Nanomed Inovação em Nanotecnologia, 13560-460 São Carlos, SP, Brazil \\ ${ }^{4}$ Instituto de Física de São Carlos (IFSC), Universidade de São Paulo (USP), 13566-590 São Carlos, SP, Brazil
}

Correspondence should be addressed to Edgar A. Sanches; sanches.ufam@gmail.com

Received 31 October 2014; Revised 5 January 2015; Accepted 6 January 2015

Academic Editor: Bin Li

Copyright (C) 2015 Edgar A. Sanches et al. This is an open access article distributed under the Creative Commons Attribution License, which permits unrestricted use, distribution, and reproduction in any medium, provided the original work is properly cited.

Ceramic nanocomposites constituted by a matrix of $\alpha-\mathrm{Al}_{2} \mathrm{O}_{3}$ microparticles reinforced by polyaniline emeraldine-salt form (PANIES) nanoparticles were prepared by in situ polymerization and characterized structural and morphologically. Peaks related to both materials were observed through XRD technique: PANI-ES presented peaks at $2 \theta=8.9,14.9,20.8,25.3,27.1$, and $30.0^{\circ}$ and in $\alpha$ - $\mathrm{Al}_{2} \mathrm{O}_{3}$ phase peaks were found at $2 \theta=25.6,35.2,37.9,43.5,52.6,57.6$, and $68.1^{\circ}$. Nanocomposite crystallinity percentage was estimated around 70\%. SEM showed a polymerization of PANI-ES over alumina plates. By Le Bail method it was observed that PANI-ES and $\alpha-\mathrm{Al}_{2} \mathrm{O}_{3}$ have crystallite average size around, respectively, 41 and $250 \AA$. By FTIR analysis characteristic absorption bands of both materials were identified. Additional bands indicating new chemical bonds were not observed, suggesting that nanocomposite was formed by physical deposition. Nanocomposite DC electrical conductivity was found around $0.24 \mathrm{~S} / \mathrm{cm}$ (against $1.84 \times 10^{-4} \mathrm{~S} / \mathrm{cm}$ for pure PANI-ES), showing an increase of about 1,300 times compared to the pure PANI-ES at room temperature. Thus, this paper showed that both materials have kept its original structural characteristics and exhibited high electrical conductivity when combined in nanocomposite form.

\section{Introduction}

Interest in nanocomposites (NCs) has grown considerably because these materials tend to exhibit better properties when compared to conventional composites [1-4]. The improvement in their properties occurs due to the fact that the interactions at the interface between matrix/reinforcement tend to increase in nanoscale [5-7]. NCs constituted by polyaniline (PANI) or its derivatives and aluminum oxide have been prepared by several methods, resulting in a range of applications [8-16].

Intrinsically conducting polymers (ICPs) have been widely studied due to its great potential in technological applications, representing a class of materials with mechanical, electrical, and optical properties similar to metals and inorganic semiconductors [17-21]. Among ICPs, polyaniline emeraldine-salt form (PANI-ES) has a prominent position due to the low cost of monomer, ease of synthesis, and doping and chemical stability [22-26]. Aluminum oxide $\left(\alpha-\mathrm{Al}_{2} \mathrm{O}_{3}\right)$ is one of the most important advanced ceramic materials due to its good corrosion resistance, hardness, good mechanical properties, and adsorption capacity, which favor its use in several technological applications [27-31].

Despite the importance of PANI in the ICPs class, there are some limitations that hinder its use in industrial scale, such as low solubility in organic solvents, low mechanical 
flexibility, and processability $[32,33]$. A widely used mechanism for improving its solubility and processability is the introduction of polar functional and long flexible alkyl groups mainly bonded to the main chain [34]. Furthermore, PANI is one of the most promising industrial alternatives to obtain nanocomposites or blends. Then, one can combine the electrical properties of PANI with mechanical properties of the insulating matrix, such as alumina [35].

Nanocomposite constituted by $\alpha-\mathrm{Al}_{2} \mathrm{O}_{3}$ microparticles reinforced by PANI-ES nanoparticles was prepared by in situ polymerization. Fourier-transform infrared spectroscopy (FTIR) was used for bonds of structural information; XRD was used for the determination of cell parameters and crystallinity percentage estimative; Le Bail method was performed to refine cell parameters and to obtain crystallite size and shape; SEM was carried out for the determination of solid nanocomposite morphology. These results were correlated with electrical properties. The crystal structure investigation of semicrystalline materials is an important research topic in many areas and remains in full development. Understanding the structure of semicrystalline nanocomposites constituted by polymer/ceramic materials is essential to the development of new technological applications.

\section{Experimental}

2.1. Nanocomposite Synthesis. PANI-ES/ $\alpha-\mathrm{Al}_{2} \mathrm{O}_{3}$ synthesis was performed based on Zhang (2006) [8] and Sanches et al. (2013) [25], with some modifications. Aniline (ANI) monomer was purchased from Sigma-Aldrich and further distilled. $\alpha-\mathrm{Al}_{2} \mathrm{O}_{3}$ was obtained from Sapra, SA; São Carlos, SP, in December 2013. Two solutions were prepared. In Solution I, $20 \mathrm{~mL}$ of distilled aniline (ANI) was dissolved in $500 \mathrm{~mL}$ of hydrochloric acid $(\mathrm{HCl}) 1.0 \mathrm{M}$, added to $167 \mathrm{~g}$ of $\alpha-\mathrm{Al}_{2} \mathrm{O}_{3}$ powder under stirring. In Solution II, $11.5 \mathrm{~g}$ of ammonium persulfate (APS) was added to $200 \mathrm{~mL}$ of hydrochloric acid $(\mathrm{HCl}) 1.0 \mathrm{M}$. Then, Solution II was rapidly added to Solution I allowing the polymerization. System remained under stirring for $3 \mathrm{~h}$. Then, the dispersion of green color with $\alpha-\mathrm{Al}_{2} \mathrm{O}_{3}$ particles was vacuum filtered and washed with acetone.

2.2. Fourier-Transformed Infrared Spectroscopy (FTIR). Infrared spectra were measured in Nanomed Inovação em Nanotecnologia in a spectrophotometer Bomem-MB SeriesHartmann and Braun in the range of $400-2000 \mathrm{~cm}^{-1}$. Samples were prepared in $\mathrm{KBr}$ pellet with mass ratio of $1: 100$.

\subsection{X-Ray Diffraction and Crystallinity Percentage. XRD data} were obtained at the Laboratory of X-ray Crystallography of IFSC/USP, São Carlos, SP, using a Rigaku Rotaflex diffractometer equipped with graphite monochromator and rotating anode tube, operating with $\mathrm{Cu} \mathrm{K} \alpha, 50 \mathrm{kV}$, and $100 \mathrm{~mA}$. Powder diffraction patterns were obtained in step scanning mode, $2 \theta=5-55^{\circ}$, step of $0.02^{\circ}$, and $3 \mathrm{~s} /$ step. Using routine software, crystallinity percentage was estimated using the diffractogram pattern and separating and then measuring the integrated intensities from the crystalline and noncrystalline phases. The integration was carried out over the whole range $2 \theta=5^{\circ}$ to $55^{\circ}$, where $\theta$ is the Bragg angle. The estimated crystallinity (E.C.), given as a percentage, was obtained by E.C. $=100 A_{c} /\left(A_{a}+A_{c}\right)$, where $A_{c}$ and $A_{a}$ are, respectively, the crystalline and noncrystalline integrated intensities [36].

2.4. Le Bail Method. The use of Le Bail whole powder pattern decomposition method [37] to obtain structural information from semicrystalline patterns is not very common due to the large overlapped peaks on diffractograms. Nevertheless it has been used to characterize polyurethane, polyaniline, and substituted polyanilines [25, 38, 39]. Le Bail method was performed using the software package FullProf [40]. All parameters were refined by the least-squares method [41]. The pseudo-Voigt function modified by ThompsonCox-Hastings was used as peak profile function [42]. Instrumental resolution function parameters were obtained from a lanthanum hexaborate standard, $\mathrm{LaB}_{6}$. Aniline tetramer single crystal parameters obtained by Evain et al. [43] were used as initial parameters for PANI phase $(a=5.7328 \AA, b=$ $8.8866 \AA, c=22.6889 \AA, \alpha=82.7481^{\circ}, \beta=84.5281^{\circ}$, and $\gamma=$ $88.4739^{\circ}$ ). Aluminum oxide structural parameters obtained by Lutterotti and Scardi [44] were used as initial parameters for alumina phase $(a=4.756 \AA, b=4.756 \AA, c=12.9636 \AA, \alpha=$ $90.0^{\circ}, \beta=90.0^{\circ}$, and $\left.\gamma=120.0^{\circ}\right)$. Anisotropic crystallite size was determined using spherical harmonics (SHP) [45-47].

2.5. SEM Analysis and DC Conductivity Measurements. SEM experiments were performed in equipment Supra 35, Carl Zeiss. Powder samples were deposited on a carbon tape and the surface morphology was obtained at room temperature. For DC conductivity measurements, samples processed into pellets were coated with silver ink on both sides in which electrical connections were made. Measurements were performed at room temperature $(300 \mathrm{~K})$ using a Keithley Model 2612 A from $500 \mathrm{mV}$ to $2 \mathrm{~V}$.

\section{Results and Discussion}

3.1. FTIR Analysis. Figure 1 shows the FTIR spectra of the nanocomposite (PANI-ES/ $\alpha-\mathrm{Al}_{2} \mathrm{O}_{3}$ ), PANI-ES, and $\alpha-\mathrm{Al}_{2} \mathrm{O}_{3}$. For PANI-ES spectrum, bands were found between 1556 and $1457 \mathrm{~cm}^{-1}$ (band 1), which were related to $\mathrm{C}=\mathrm{C}$ double bonds; bands between 1300 and $1234 \mathrm{~cm}^{-1}$ (band 2) are due to the C$\mathrm{N}$ stretching; a band located at $1132 \mathrm{~cm}^{-1}$ (band 3) is attributed to vibration of $\mathrm{C}-\mathrm{H}$ bond and $794 \mathrm{~cm}^{-1}$ (band 4) to the out-of-plane angular vibration of $\mathrm{C}-\mathrm{H}$ aromatics. Regarding the $\alpha-\mathrm{Al}_{2} \mathrm{O}_{3}$ phase, bands between 649 and $457 \mathrm{~cm}^{-1}$ correspond to the condensed $\mathrm{AlO}_{6}$ octahedra which compose the building blocks in $\alpha-\mathrm{Al}_{2} \mathrm{O}_{3}$ structure [48]. Thus, in the FTIR nanocomposite spectrum bands related to both materials were observed. No additional bands related to new chemical bonds were found, suggesting that the nanocomposite was formed by physical deposition.

3.2. X-Ray Diffraction and Crystallinity Percentage. By XRD technique the diffraction pattern of the nanocomposite 


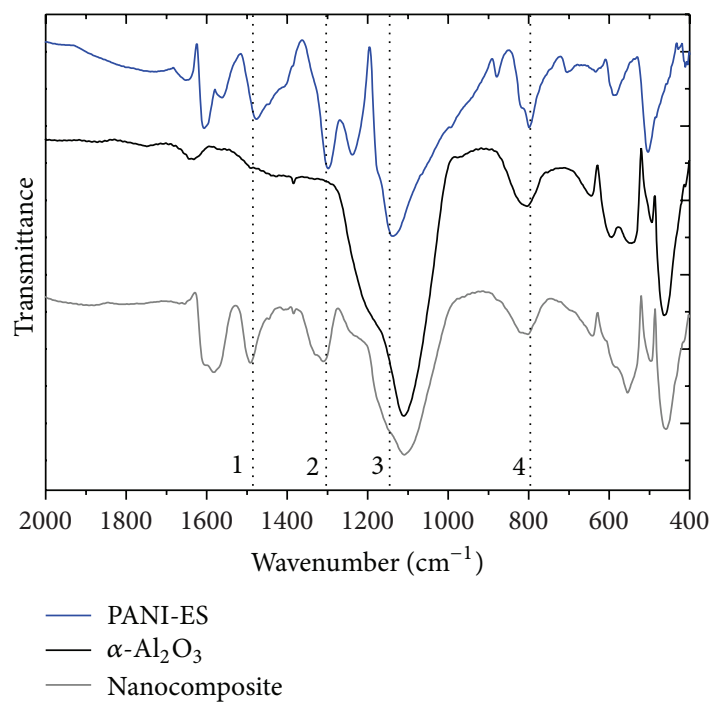

FIGURE 1: FTIR of PANI-ES, $\alpha-\mathrm{Al}_{2} \mathrm{O}_{3}$, and nanocomposite.

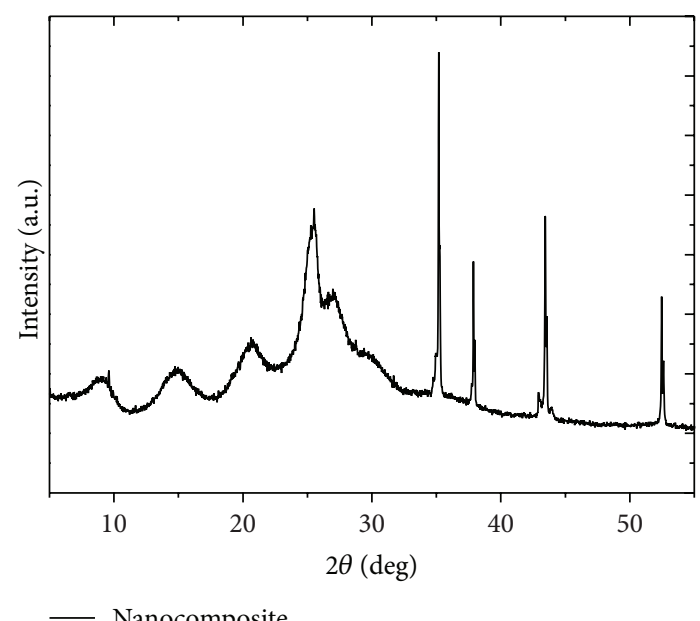

FIGURE 2: Nanocomposite X-ray diffraction pattern.

PANI-EB $/ \alpha-\mathrm{Al}_{2} \mathrm{O}_{3}$ was obtained. Peaks related to both materials were observed in diffractogram. With respect to PANIES, peaks were found at $2 \theta=8.9,14.9,20.8,25.3,27.1$, and $30.0^{\circ}$ [25] and for $\alpha-\mathrm{Al}_{2} \mathrm{O}_{3}$ phase peaks were present at $2 \theta=25.6,35.2,37.9,43.5$, and $52.6^{\circ}$ [44]. Figure 2 shows the nanocomposite XRD pattern. Crystallinity percentage was estimated from the whole nanocomposite XRD pattern. Figure 3 shows the superposition of the diffraction pattern of nanocomposite (PANI-ES/ $\alpha-\mathrm{Al}_{2} \mathrm{O}_{3}$ ) (black), the supposed profile related to the noncrystalline phase (red), and the corresponding profile of the supposed crystalline phase (dark blue). Nanocomposite crystallinity percentage was estimated around $70 \%$.

3.3. SEM Analysis and DC Conductivity Measurements. Scanning electron microscopy (SEM) technique revealed that the ceramic material has particles with a range of micrometric sizes with plates-like morphology. For PANI-ES

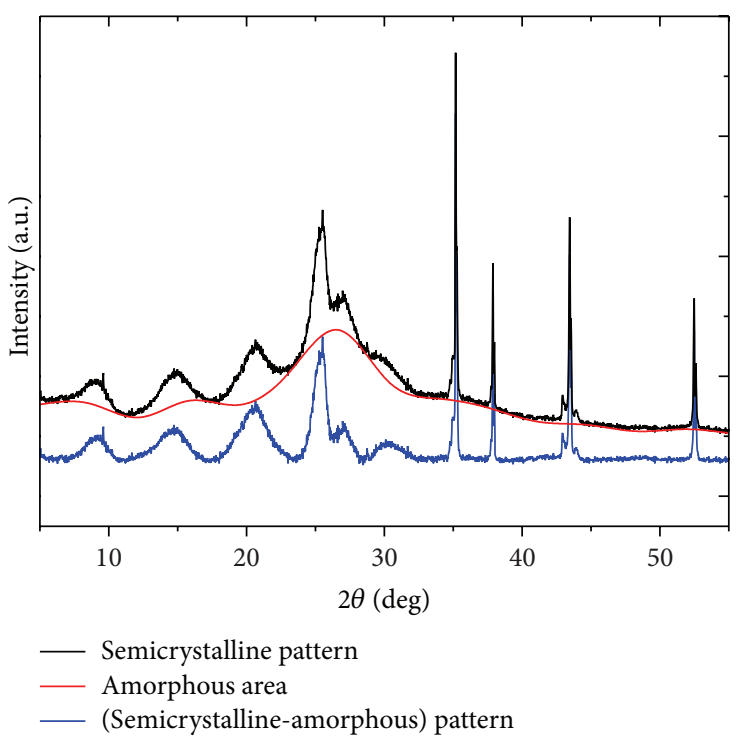

FIgure 3: Decomposition of the POEA-ES diffraction peaks.

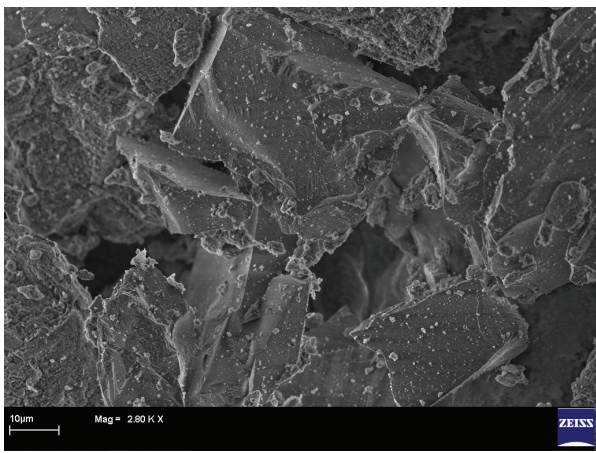

Figure 4: SEM image of $\alpha-\mathrm{Al}_{2} \mathrm{O}_{3}$.

nanosized particles with morphologies similar to interconnected nanospheres were observed, which form the polymer nanofibers. Figures 4, 5(a), and 5(b) show, respectively, the morphologies of alumina and PANI-ES. In the nanocomposite it was observed that polymerization of PANI-ES occurred on the $\alpha-\mathrm{Al}_{2} \mathrm{O}_{3}$ plates by physical deposition (as suggested by FTIR analysis), being possible to observe in Figures 6(a)-6(c) the morphology of both materials combined in nanocomposite form.

An increasing about 1,300 times in nanocomposite DC electrical conductivity $(0.24 \mathrm{~S} / \mathrm{cm})$ was verified when compared to the pure sample of PANI-ES [25]. This is surprising since alumina is an electrical insulator with DC electrical conductivity about $10^{-14} \mathrm{~S} / \mathrm{cm}$. The pure PANI-ES conductivity was found around $1.84 \times 10^{-4} \mathrm{~S} / \mathrm{cm}$ for Sanches et al. [25], as expected.

We suggest that the most compact PANI-ES interface between the $\alpha-\mathrm{Al}_{2} \mathrm{O}_{3}$ plates contributed significantly to increasing the nanocomposite DC electrical conductivity. The conductive polymer over the $\alpha-\mathrm{Al}_{2} \mathrm{O}_{3}$ plates surface (percolation threshold) might promoted easier paths for the charge carriers. Zhang [8] obtained a conductive value 


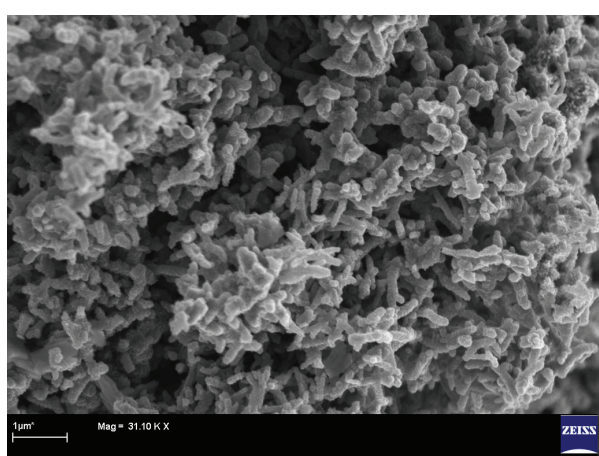

(a)

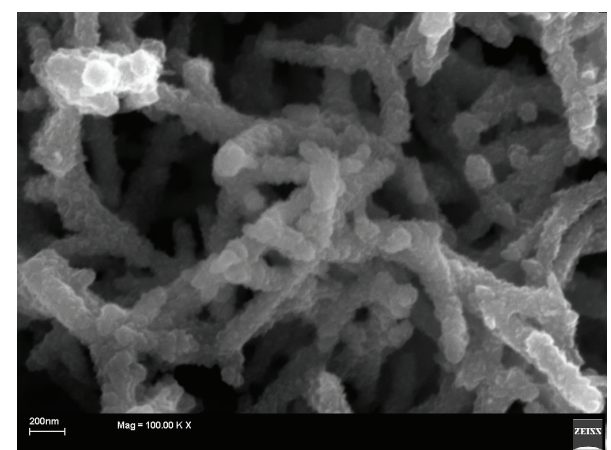

(b)

FIGURE 5: SEM image of PANI-ES with increase of (a) 31,000 and (b) 100,000 times.

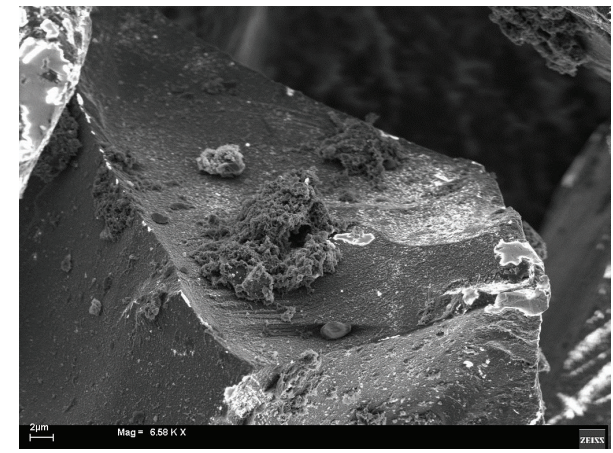

(a)

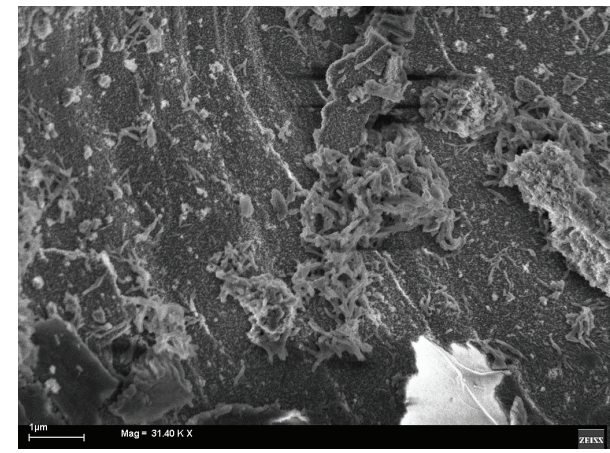

(b)

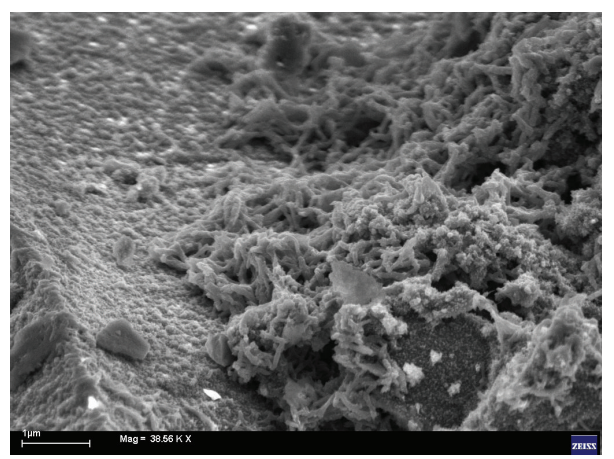

(c)

FIGURE 6: SEM images of PANI-ES/ $\alpha-\mathrm{Al}_{2} \mathrm{O}_{3}$ nanocomposite.

of $0.17 \mathrm{~S} / \mathrm{cm}$ for core-shell structured alumina-polyaniline particles. Michálek et al. [49] studied the electrical conductivity in alumina/multiwall carbon nanotubes (MWCNT) that obtained an increase from $10^{-14} \mathrm{~S} / \mathrm{cm}$ (pure alumina) to $2.7 \cdot 10^{-3} \mathrm{~S} / \mathrm{cm}$ for composites. However, the DC electrical conductivity can decrease in the case of a better interaction between the composite components: Teoh et al. [50] synthesized nanofibers composite by oxidative polymerization of aniline with alumina nanofibers and the DC electrical conductivity decreased with increasing alumina nanofibers from $0.18 \mathrm{~S} / \mathrm{cm}$ to $10^{-3} \mathrm{~S} / \mathrm{cm}$ for alumina loading from $0 \%$ to $20 \%$.
3.4. Le Bail Method Analysis. A process using iteratively the Rietveld decomposition formula for whole powder pattern decomposition (WPPD) purposes was first applied in 1988 [37] and called much later the "Le Bail method" or "Le Bail fit," or "pattern matching" as well as "profile matching" in the FullProf Rietveld program [40]. In the original computer program first applying that method, arbitrarily all equal $S_{k \text { (calc) }}^{2}$ values are first used, instead of using structure factors calculated from the atomic coordinates, resulting in " $I_{k(\mathrm{obs})}$ " which are then reinjected as new $S_{k(\text { calc })}^{2}$ values at the next iteration, while the usual profile and cell parameters (but not the scale) are refined by least squares. Equipartition of 
TABLE 1: Comparison between the values found by Evain et al. (2002) [43] and Lutterotti and Scardi (1990) [44] with those found by PANI-ES and $\alpha-\mathrm{Al}_{2} \mathrm{O}_{3}$, respectively, through Le Bail method.

\begin{tabular}{|c|c|c|c|c|}
\hline Refined parameters & $\begin{array}{c}\text { Evain et al., (2002) } \\
{[43]}\end{array}$ & PANI-ES & $\begin{array}{c}\text { Lutterotti and } \\
\text { Scardi (1990) } \\
\end{array}$ & $\alpha-\mathrm{Al}_{2} \mathrm{O}_{3}$ \\
\hline$a(\AA)$ & $5.7328(1)$ & 5.754363 & $4.7540(5)$ & 4.756846 \\
\hline$b(\AA)$ & $8.8866(2)$ & 8.855334 & $4.7540(5)$ & 4.756846 \\
\hline$c(\AA)$ & $22.6889(6)$ & 22.961094 & $12.9820(6)$ & 12.966290 \\
\hline$\alpha\left(^{\circ}\right)$ & $82.7481(8)$ & 84.222496 & 90 & 90 \\
\hline$\beta\left(^{\circ}\right)$ & $84.5281(8)$ & 84.180656 & 90 & 90 \\
\hline$\gamma\left({ }^{\circ}\right)$ & $88.4739(11)$ & 88.148727 & 120 & 120 \\
\hline$V\left(\AA^{3}\right)$ & $1141.3(4)$ & 1160 & 254.1 & 254.0 \\
\hline Global average size (anisotr.) $(\AA)$ & - & $41(10)$ & - & $250(40)$ \\
\hline Crystallite apparent size $_{100}(\AA)$ & - & 46 & - & 140 \\
\hline Crystallite apparent size $_{010}(\AA)$ & - & 30 & - & 140 \\
\hline Crystallite apparent $\operatorname{size}_{001}(\AA)$ & - & 35 & - & 90 \\
\hline$R_{\mathrm{wp}}(\%)$ & \multicolumn{4}{|c|}{9.3} \\
\hline$R_{p}(\%)$ & \multicolumn{4}{|c|}{5.1} \\
\hline$\chi^{2}$ & \multicolumn{4}{|c|}{6.6} \\
\hline
\end{tabular}

exactly overlapping reflections comes from the strictly equal result for Bragg peaks at the same angles which would have starting equal calculated intensities. Not starting from a set of all equal $S_{k(\text { calc })}^{2}$ values would produce $I_{k(\text { obs })}$ values keeping the same original ratio for the exactly overlapping reflections. It is understandable that such an iterative process requires as good starting cell and profile parameters as the Rietveld method itself [51].

To perform Le Bail method the crystal symmetry and unit cell for PANI and aluminum oxide obtained, respectively, by Evain et al. [43] and Lutterotti and Scardi [44] were used as input data. The refinement steps were followed by refining the peak width, refinement of $a, b$, and $c$ and $a, b, c, \alpha, \beta$, and $\gamma$. This sequence was addressed for both phases. Figure 7 shows the final refinement, with the observed ( $I_{\text {obs }}$, black) and the calculated $\left(I_{\text {calc }}\right.$, red) diffractograms, as well as the residual line $\left(I_{\mathrm{obs}}-I_{\mathrm{calc}}\right.$, blue). Table 1 shows the refined parameters.

The refined parameters values were compared with those obtained in literature $[43,44]$. It is important to stress that the standard deviation appearing in the global average apparent size is calculated using the reciprocal lattice directions so it is a measure of the degree of anisotropy, not of the estimated error. The crystallite size projections for ES-PANI are showed in Figure 8(a). The crystallite shape can be described as a prolate ellipsoidal shape with its longer axis roughly parallel to [110] [25]. There was an average crystallite size around $41 \AA$ with standard deviation (anisotropy) of $10 \AA$. There are a smaller apparent size of 30 and $35 \AA$ in the [010] and [001] directions, respectively, and others almost equivalent (46 $)$ along [100]. The crystallite size projections for $\alpha-\mathrm{Al}_{2} \mathrm{O}_{3}$ are showed in Figure 8(b). There was an average crystallite size around $250 \AA$ with standard deviation (anisotropy) of $40 \AA$. There is a largest apparent size of $140 \AA$ in the [100] and [010] directions, and other smaller (90 A) along [001]. Through Le Bail method it was verified that nanocomposite phases have

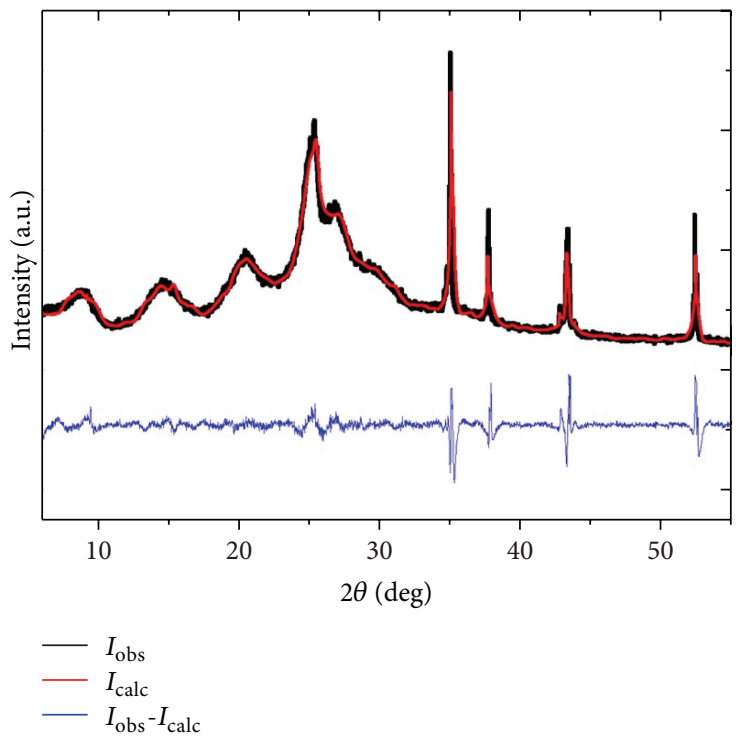

FIGURE 7: Le Bail method applied to nanocomposite.

kept its lattice parameters and provide structural information about crystallite size and shape.

\section{Conclusions}

We successfully obtained polyaniline emeraldine-salt form/ $\alpha$-aluminum oxide (PANI-ES $/ \alpha-\mathrm{Al}_{2} \mathrm{O}_{3}$ ) nanocomposite by in situ polymerization. XRD analysis showed that nanocomposite presents a semicrystalline pattern (with estimated crystallinity around 70\%) with peaks related to both materials. SEM analysis showed that PANI-ES was polymerized over the $\alpha-\mathrm{Al}_{2} \mathrm{O}_{3}$ plates. 

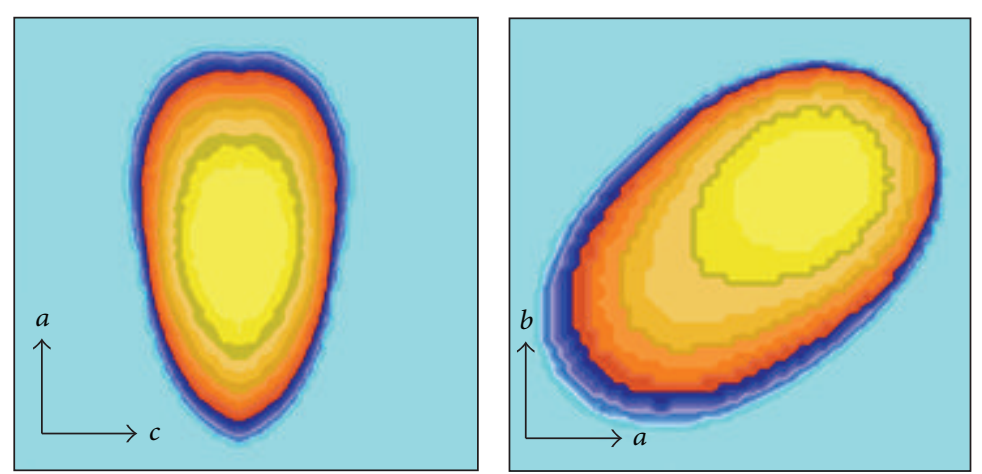

(a)
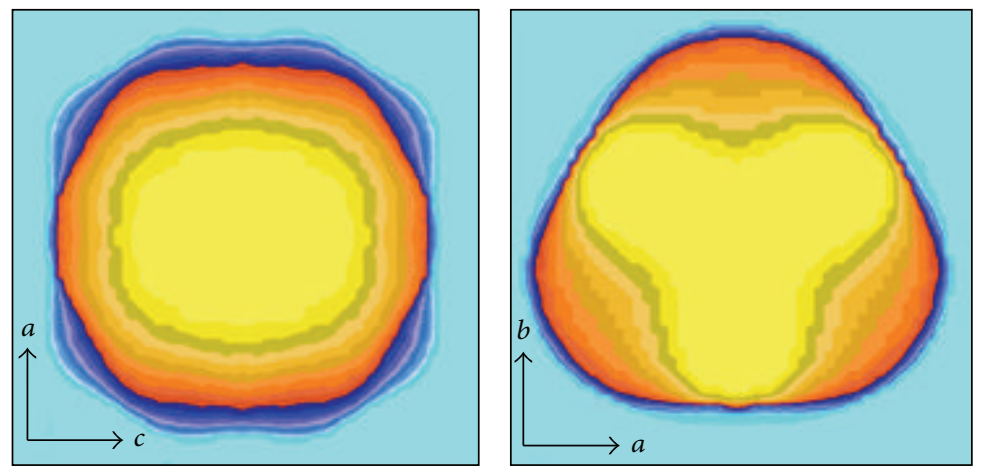

(b)
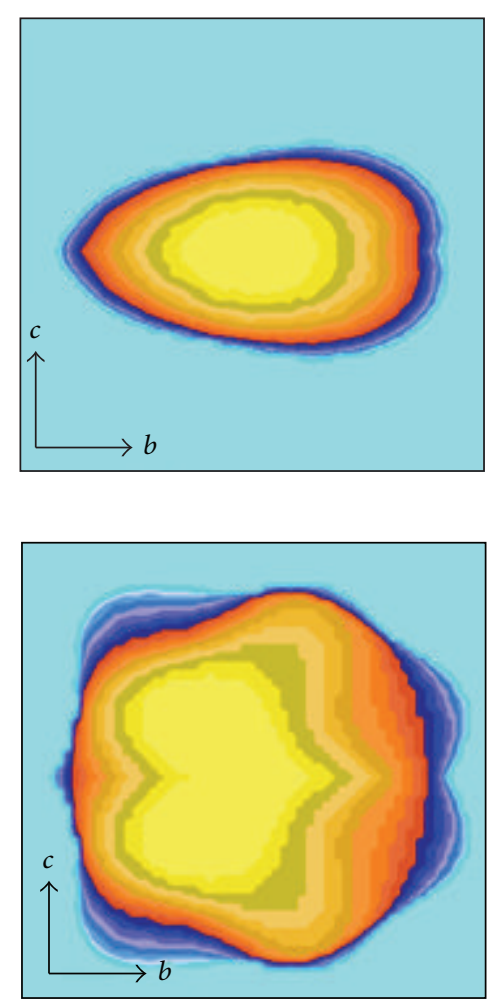

Figure 8: Crystallite shapes for (a) PANI-ES and (b) $\alpha-\mathrm{Al}_{2} \mathrm{O}_{3}$.

FTIR technique revealed that nanocomposite has characteristic absorption bands related to both materials, suggesting that nanocomposite has preserved the original structural characteristics of its constituents. Conducting polymer/inorganic nanocomposite can be classified into two types: physical deposition, in which the polymer is absorbed on the surface of inorganic particles, and chemical deposition, in which there is a covalent bond between them [11]. So, FTIR analysis showed that there was no chemical interaction between PANI-ES and $\alpha-\mathrm{Al}_{2} \mathrm{O}_{3}$.

The great contribution of this work is to obtain structural information using the Le Bail whole powder pattern decomposition method applied to a semicrystalline system consisting of semicrystalline polymeric/highly crystalline ceramic materials. The purpose of this work is also to promote this important structural characterization tool, which can be properly applied for semicrystalline materials. This method allowed the determination of cell parameters and crystallite size/shape for all phases. The refined cell parameters, so closed to the original values, showed that all phases have kept its structural characteristics after synthesis. For PANIES and $\alpha-\mathrm{Al}_{2} \mathrm{O}_{3}$ there were, respectively, average crystallite sizes around 41 and $250 \AA$.

With respect to conductivity measurements, this work showed that it is possible to increase the conductivity of polyaniline by synthesizing a nanocomposite using an insulating matrix. It was observed that the polymerization of PANI-ES over $\alpha-\mathrm{Al}_{2} \mathrm{O}_{3}$ particles promoted an increasing of conductivity around 1,300 times when compared to pure sample of PANI-ES. To explain this increasing in conductivity, we suggested that the interface between PANI-ES/ $\alpha$ $\mathrm{Al}_{2} \mathrm{O}_{3}$ probably created easier paths for charge carriers in nanocomposite. We hope that the structural information provided in this study may be useful in the area of materials science and, more specifically, in several technological applications that require conducting nanocomposites with electrical conductivity in the obtained range.

\section{Conflict of Interests}

The authors declare that there is no conflict of interests regarding the publication of this paper.

\section{Acknowledgment}

The authors are grateful to the Brazilian Agency FAPEAM (Fundação de Amparo à Pesquisa do Estado do Amazonas) for the financial support to this work based on the Edital Papac 020/2013.

\section{References}

[1] M. A. Souza, L. A. Pessan, and A. Rodolfo Jr., "Nanocompósitos de Poli(Cloreto de Vinila)(PVC)/argilas organofílicas," Polímeros: Ciência e Tecnologia, vol. 16, no. 4, pp. 257-262, 2006. 
[2] R. Botan, T. R. Nogueira, L. M. F. Lona, and F. Wypych, "Síntese e caracterização de Nanocompósitos Esfoliados de Poliestireno-Hidróxido Duplo Lamelar via polimerização in situ," Polímeros, vol. 21, no. 1, pp. 34-38, 2011.

[3] R. Ramasubramaniam, J. Chen, and H. Liu, "Homogeneous carbon nanotube/polymer composites for electrical applications," Applied Physics Letters, vol. 83, no. 14, pp. 2928-2930, 2003.

[4] A. C. C. Esteves, A. Barros-Timmons, and T. Trindade, "Nanocompósitos de matriz polimérica: estratégias de síntese de materiais híbridos," Química Nova, vol. 27, no. 5, pp. 798806, 2004.

[5] M. Alexandre and P. Dubois, "Polymer-layered silicate nanocomposites: preparation, properties and uses of a new class of materials," Materials Science and Engineering R: Reports, vol. 28, no. 1-2, pp. 1-63, 2000.

[6] P. H. C. Camargo, K. G. Satyanarayana, and F. Wypych, "Nanocomposites: synthesis, structure, properties and new application opportunities," Materials Research, vol. 12, no. 1, pp. $1-39,2009$.

[7] R. A. Vaia and E. P. Giannelis, "Polymer nanocomposites: status and opportunities," Materials Research Society Bulletin, vol. 26, no. 5, pp. 394-401, 2001.

[8] D. Zhang, "Preparation of core-shell structured aluminapolyaniline particles and their application for corrosion protection," Journal of Applied Polymer Science, vol. 101, no. 6, pp. 4372-4377, 2006.

[9] Y. He, "Synthesis of polyaniline/nano- $\mathrm{CeO}_{2}$ composite microspheres via a solid-stabilized emulsion route," Materials Chemistry and Physics, vol. 92, no. 1, pp. 134-137, 2005.

[10] Y.-N. Qi, F. Xu, H.-J. Ma, L.-X. Sun, J. Zhang, and T. Jiang, "Thermal stability and glass transition behavior of PANI $/-\mathrm{Al}_{2} \mathrm{O}_{3}$ composites," Journal of Thermal Analysis and Calorimetry, vol. 91, no. 1, pp. 219-223, 2008.

[11] M. R. Nabid, M. Golbabaee, A. B. Moghaddam, A. R. Mahdavian, and M. M. Amini, "Preparation of the $\gamma-\mathrm{Al}_{2} \mathrm{O}_{3} / \mathrm{PANI}$ nanocomposite via enzymatic polymerization," Polymer Composites, vol. 30, no. 6, pp. 841-846, 2009.

[12] G. B. Oliveira, J. L. L. Filho, M. E. C. Chaves, W. M. Azevedo, and L. B. Carvalho Jr., "Enzyme immobilization on anodic aluminum oxide/polyethyleneimine or polyaniline composites," Reactive and Functional Polymers, vol. 68, no. 1, pp. 27-32, 2008.

[13] J. Zhu, S. Wei, L. Zhang et al., "Electrical and dielectric properties of polyaniline- $\mathrm{Al}_{2} \mathrm{O}_{3}$ nanocomposites derived from various $\mathrm{Al}_{2} \mathrm{O}_{3}$ nanostructures," Journal of Materials Chemistry, vol. 21, no. 11, pp. 3952-3959, 2011.

[14] J.-M. Yeh and C.-P. Chin, "Structure and properties of poly $(o-$ methoxyaniline)-clay nanocomposite materials," Journal of Applied Polymer Science, vol. 88, no. 4, pp. 1072-1080, 2003.

[15] C. Eiras, I. N. G. Passos, A. C. F. De Brito et al., "Nanocompósitos eletroativos de Poli(o-metoxianilina) e polissacarídeos naturais," Química Nova, vol. 30, no. 5, pp. 1158-1162, 2007.

[16] M. Ates, "A review study of (bio)sensor systems based on conducting polymers," Materials Science and Engineering C, vol. 33, no. 4, pp. 1853-1859, 2013.

[17] M. Angelopoulos, G. E. Asturias, S. P. Ermer et al., "Polyaniline: solutions, films and oxidation state," Molecular Crystal Liquid Crystal, vol. 160, no. 1, pp. 151-163, 1988.

[18] S. Bhadra and D. Khastgir, "Determination of crystal structure of polyaniline and substituted polyanilines through powder Xray diffraction analysis," Polymer Testing, vol. 27, no. 7, pp. 851$857,2008$.
[19] S. Bhadra, N. K. Singha, and D. Khastgir, "Electrochemical synthesis of polyaniline and its comparison with chemically synthesized polyaniline," Journal of Applied Polymer Science, vol. 104, no. 3, pp. 1900-1904, 2007.

[20] D. Nicolas-Debarnot and F. Poncin-Epaillard, "Polyaniline as a new sensitive layer for gas sensors," Analytica Chimica Acta, vol. 475, no. 1-2, pp. 1-15, 2003.

[21] J.-H. Sung, S.-J. Kim, and K.-H. Lee, "Preparation of compact polyaniline films: electrochemical synthesis using agar gel template and charge-storage applications," Journal of Power Sources, vol. 126, no. 1-2, pp. 258-267, 2004.

[22] R. Faez, C. Reis, P. S. Freitas, O. K. Kosima, G. Ruggeri, and M. A. de Paoli, "Polímeros Condutores," Química Nova na Escola, vol. 11, no. 1, pp. 13-18, 2000.

[23] E. M. Geniès, A. Boyle, M. Lapkowski, and C. Tsintavis, "Polyaniline: a historical survey," Synthetic Metals, vol. 36, no. 2, pp. 139-182, 1990.

[24] J. P. Pouget, M. E. Jozefowicz, A. J. Epstein, X. Tang, and A. G. MacDiarmid, "X-ray structure of polyaniline," Macromolecules, vol. 24, no. 3, pp. 779-789, 1991.

[25] E. A. Sanches, J. C. Soares, A. C. Mafud, E. G. R. Fernandes, F. L. Leite, and Y. P. Mascarenhas, "Structural characterization of Chloride Salt of conducting polyaniline obtained by XRD, SAXD, SAXS and SEM," Journal of Molecular Structure, vol. 1036, pp. 121-126, 2013.

[26] E. T. Kang, K. G. Neoh, and K. L. Tan, "Polyaniline: a polymer with many interesting intrinsic redox states," Progress in Polymer Science, vol. 23, no. 2, pp. 277-324, 1998.

[27] M. S. Akselrod, V. S. Kortov, D. J. Kravetsky, and V. I. Gotlib, "Highly sensitive thermoluminescent anion-defect $\alpha-\mathrm{Al}_{2} \mathrm{O}_{3}: \mathrm{C}$ single crystal detectors," Radiation Protection Dosimetry, vol. 33, no. 1-4, pp. 119-122, 1990.

[28] J. Zhu, S. Wei, L. Zhang et al., "Electrical and dielectric properties of polyaniline- $\mathrm{Al}_{2} \mathrm{O}_{3}$ nanocomposites derived from various $\mathrm{Al}_{2} \mathrm{O}_{3}$ nanostructures," Journal of Materials Chemistry, vol. 21, no. 11, pp. 3952-3959, 2011.

[29] S. V. Jadhav and V. Puri, "Microwave study of chemically synthesized conducting polyaniline on alumina," Synthetic Metals, vol. 158, no. 21-24, pp. 883-887, 2008.

[30] L. Nascimento, F. Vanhavere, E. Silva, and Y. de Deene, "A shorttime fading study of $\mathrm{Al}_{2} \mathrm{O}_{3}: \mathrm{C}$," Radiation Physics and Chemistry, vol. 106, pp. 26-32, 2015.

[31] L. F. Nascimento, C. V. Saldarriaga, F. Vanhavere, E. D’Agostino, G. Defraene, and Y. de Deene, "Characterization of OSL $\mathrm{Al}_{2} \mathrm{O}_{3}: \mathrm{C}$ droplets for medical dosimetry," Radiation Measurements, vol. 56, pp. 200-204, 2013.

[32] D. Gonçalves, D. S. dos Santos Jr., L. H. C. Mattoso, F. E. Karasz, L. Akcelrud, and R. M. Faria, "Poly(o-methoxyaniline): solubility, deprotonation-protonation process in solution and cast films," Synthetic Metals, vol. 90, no. 1, pp. 5-11, 1997.

[33] L. H. Dao, M. Leclerc, J. Guay, and J. W. Chevalier, "Synthesis and characterization of substituted poly(anilines)," Synthetic Metals, vol. 29, no. 1, pp. 377-382, 1989.

[34] D. Macinnes Jr. and B. L. Funt, "Poly-o-methoxyaniline: a new soluble conducting polymer," Synthetic Metals, vol. 25, no. 3, pp. 235-242, 1988.

[35] J. Anand, P. S. Rao, S. Palaniappan, and D. N. Sathyanarayana, " $\mathrm{ZnCl}_{2}$-induced changes in the electronic properties of polyaniline- $\mathrm{HCl}$ salt and its base," Synthetic Metals, vol. 95, no. 1, pp. 57-62, 1998. 
[36] P. G. Stern and E. Segerman, "On the structure of polypropylene fibres," Polymer, vol. 9, pp. 471-477, 1968.

[37] A. Le Bail, H. Duroy, and J. L. Fourquet, "Ab-initio structure determination of $\mathrm{LiSbWO}_{6}$ by X-ray powder diffraction," Materials Research Bulletin, vol. 23, no. 3, pp. 447-452, 1988.

[38] F. L. Leite, W. F. Alves, M. Mir et al., “TEM, XRD and AFM study of poly(o-ethoxyaniline) films: new evidence for the formation of conducting islands," Applied Physics A: Materials Science and Processing, vol. 93, no. 2, pp. 537-542, 2008.

[39] G. Trovati, E. A. Sanches, S. M. de Souza et al., "Rigid and semi rigid polyurethane resins: a structural investigation using DMA, SAXS and LeBail method," Journal of Molecular Structure, vol. 1075, pp. 589-593, 2014.

[40] J. Rodríguez-Carvajal, "Recent developments of the program FullProf," IUCr Commission on Powder Diffraction Newsletter, vol. 26, pp. 12-19, 2001.

[41] G. S. Pawley, "Unit-cell refinement from powder diffraction scans," Journal of Applied Crystallography, vol. 14, no. 6, pp. 357361, 1981.

[42] P. Thompson, D. E. Cox, and J. B. Hastings, "Rietveld refinement of debye-scherrer synchrotron X-ray data from $\mathrm{Al}_{2} \mathrm{O}_{3}$," Journal of Applied Crystallography, vol. 20, part 2, pp. 79-83, 1987.

[43] M. Evain, S. Quillard, B. Corraze, W. Wang, and A. G. MacDiarmid, "A phenyl-end-capped tetramer of aniline," Acta Crystallographica E: Structures Reports Online, vol. 58, no. 3, pp. o343-o0344, 2002.

[44] L. Lutterotti and P. Scardi, "Simultaneous structure and sizestrain refinement by the Rietveld method," Journal of Applied Crystallography, vol. 23, no. 4, pp. 246-252, 1990.

[45] N. C. Popa, "The (hkl) dependence of diffraction-line broadening caused by strain and size for all laue groups in rietveld refinement," Journal of Applied Crystallography, vol. 31, no. 2, pp. 176-180, 1998.

[46] A. Le Bail, "New developments in microsctructre analysis via Rietveld refinement," Advances in X-Ray Analysis, vol. 42, pp. 191-203, 2000.

[47] J. Rodríguez-Carvajal and T. Roisnel, "Line broadening analysis using FULLPROF: determination of microstructural properties," Materials Science Forum, vol. 443-444, no. 2, pp. 123-126, 2004.

[48] M. C. Grasselii and A. E. Lavat, "Phase evolution preparation of spinel-containing refractory cements from Argentine dolomite," Advances in Technology of Materials and Materials Processing Journal, vol. 9, no. 1, pp. 103-108, 2007.

[49] M. Michálek, J. Sedláček, M. Parchoviansky, M. Michálková, and D. Galusek, "Mechanical properties and electrical conductivity of alumina/MWCNT and alumina/zirconia/MWCNT composites," Ceramics International, vol. 40, no. 1, pp. 12891295, 2014.

[50] G. L. Teoh, K. Y. Liew, and W. A. K. Mahmood, "Preparation of polyaniline- $\mathrm{Al}_{2} \mathrm{O}_{3}$ composites nanofibers with controllable conductivity," Materials Letters, vol. 61, no. 27, pp. 4947-4949, 2007.

[51] A. le Bail, "Whole powder pattern decomposition methods and applications: a retrospection," Powder Diffraction, vol. 20, no. 4, pp. 316-326, 2005. 

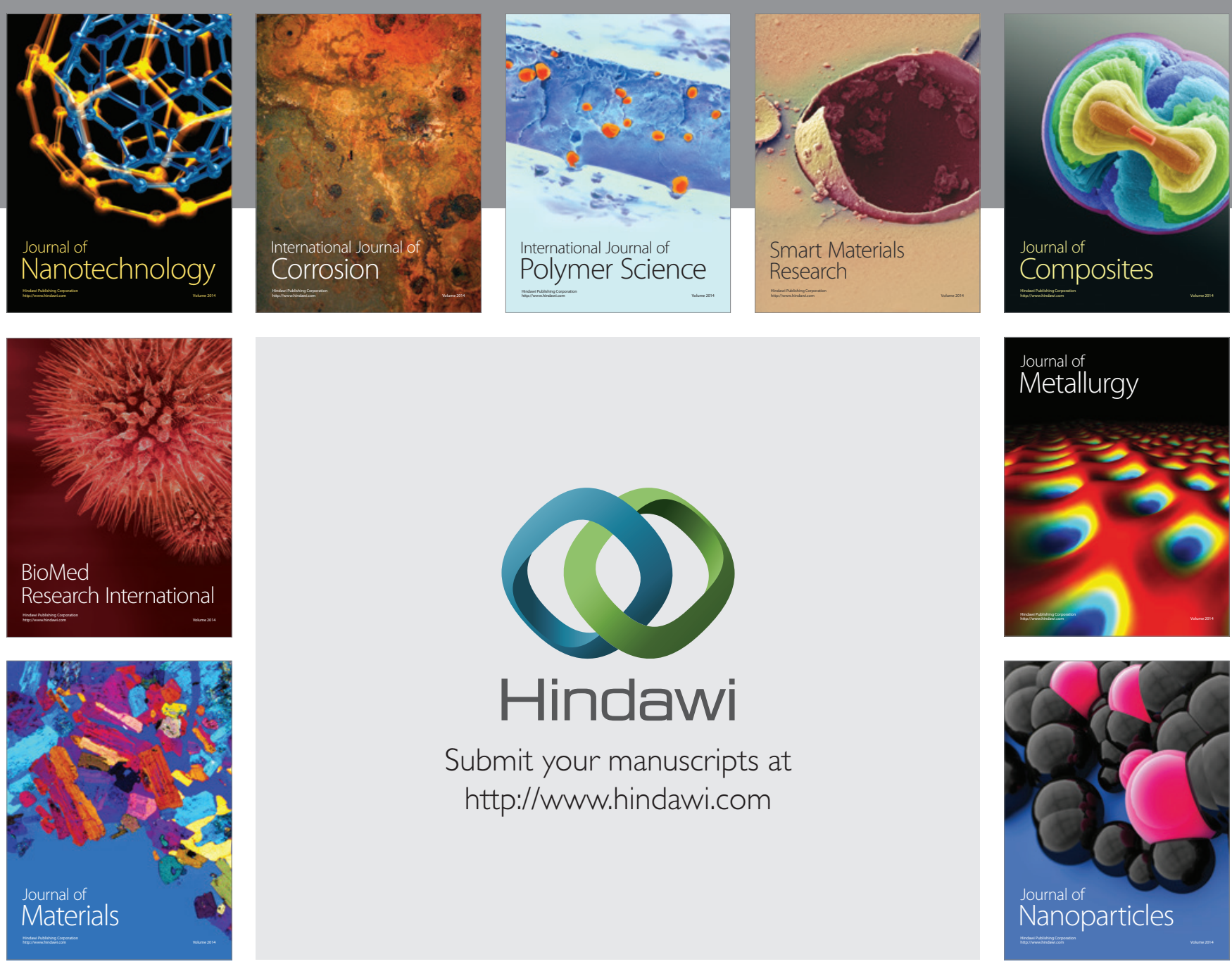

Submit your manuscripts at http://www.hindawi.com
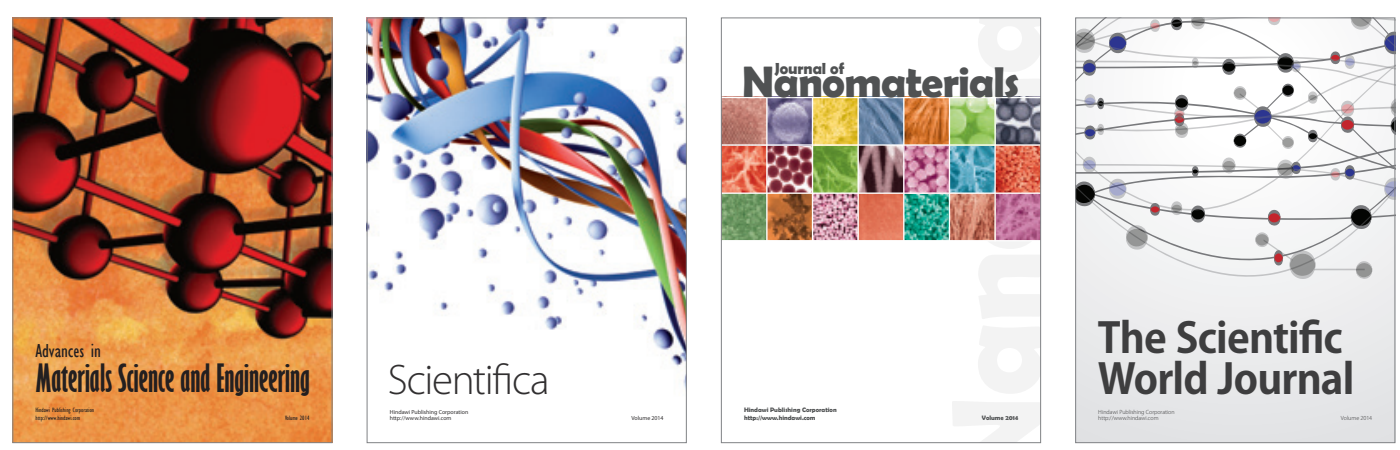

\section{The Scientific World Journal}
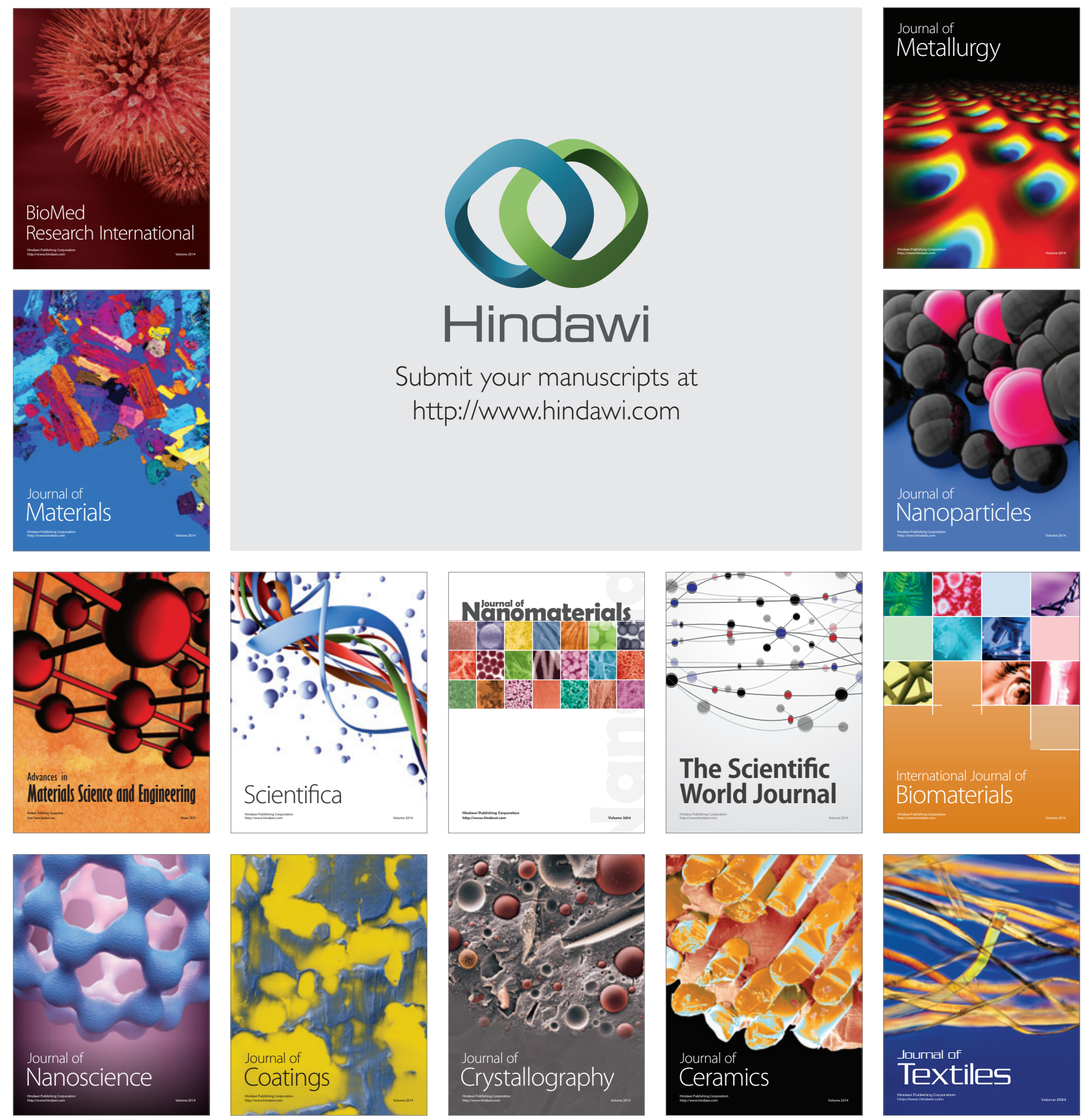